on the lungs is greatest and causes airway closure. ${ }^{9}$ The timing of individual crackles is determined by the changes in transpulmonary pressure and in lung volumes during inspiration. ${ }^{10}$ The quantity of crackles correlates well with the radiological appearances and physiological disturbance in these diseases. In granulomatous diseases affecting the lungs, such as sarcoidosis, crackles are much less common, and there is little correlation with the number of granulomas present in airways. ${ }^{9}$

Patients with chronic airways obstruction often have early inspiratory crackles which are easily heard at the mouth. These are usually fewer and of lower pitch than late inspiratory crackles of fibrosing lung disease. ${ }^{11}$ They are conducted to the lower zones and the mouth, suggesting that they are caused by changes in the larger proximal airways of the lower lobes by either excess secretions or degenerative changes in the walls of the bronchi.

Interpreting recordings of lung sounds still lacks the precision reached with phonocardiography, but the future lies with non-invasive investigations, and further studies should refine the technique.

${ }^{1}$ Robertson, A J, and Coope, R, Lancet, 1957, 2, 417.

2 Forgacs, P, Lancet, 1967, 2, 203.

${ }^{3}$ Forgacs, P, Chest, 1978, 73, 399.

${ }^{4}$ Forgacs, P, Lung Sounds, p 34. London, Baillière Tindall, 1978.

5 Ploy-Song-Sang, Y, et al, American Review of Respiratory Disease, 1977 116, 187.

' Leblanc, P, Macklem, P T, and Ross, W R D, American Review of Respiratory Disease, 1970, 102, 10.

7 Pardee, N E, Martin, C J, and Morgan, E H, Chest, 1976, 70, 341.

${ }^{8}$ Bohadana, A B, Peslin, R, and Uffholtz, H, Thorax, 1978, 33, 345

${ }^{9}$ Epler, G R, Carrington, C B, and Gaensler, E A, Chest, 1978, 73, 333.

10 Nath, A R, and Capel, L H, Thorax, 1974, 29, 695 .

11 Nath, A R, and Capel, L H, Thorax, 1974, 29, 223.

\section{Endocrine basis for sexual dysfunction in men}

Impotence is so often due to psychological factors that its endocrine causes may easily be overlooked; yet these may be specific and treatable. The latest addition (reflecting current research fashions) is hyperprolactinaemia. Franks et $a l^{1}$ recently described 29 men with raised prolactin concentrations and pituitary tumours, mainly of the "prolactinoma" variety. All but six patients had impaired sexual function. When treatment was given to reduce prolactin concentrations circulating testosterone returned towards normal and sexual function returned.

These interesting findings pose two questions. Firstly, should we routinely screen men with impotence for raised prolactin concentrations? We need information from endocrine studies of men attending sexual problem clinics before an answer can be given. The incidence of hyperprolactinaemia is lower in men than in women, and it seems likely to be a rare cause of sexual dysfunction. Furthermore, the condition seems unlikely to be found as an isolated abnormality with no clinical indications. Franks et $a l^{1}$ found that nearly all their impotent men had clinical evidence of hypogonadism and lowered testosterone concentrations. Thorner and Besser, ${ }^{2}$ on the other hand, reported a more varied association between abnormalities in prolactin concentrations and other endocrine disturbances. While undoubtedly prolactin concentrations should be measured in men with hypogonadism or with low testosterone concentrations, there is less justification for adding it to the list of routine investigations in impotence.

The second question concerns the explanation for the association between raised prolactin concentrations and impotence. In most respects, prolactin remains an enigmatic hormone. Hyperprolactinaemia is most usually treated with dopaminergic agents such as bromocriptine, which have other central and peripheral effects in addition to inhibiting the production of prolactin. Thus the sexual consequences of lowering prolactin concentrations may be due to reducing a direct prolactin effect, to raising testosterone concentrations, or to some dopaminergic effect on the brain.

What is the likelihood that the lowered testosterone concentrations found with hyperprolactinaemia are responsible for the impotence? Some testosterone is assumed to be necessary for normal sexual response; but how much remains uncertain, and this assumption has until recently lacked properly controlled studies to support it. Such studies of androgen replacement in hypogonadal men are now being done, and early results are confirming the clinical impression. ${ }^{3}$

Nevertheless, the relative importance of low testosterone concentrations as a cause of impotence remains obscure. Endocrine studies of impotent men have found both normal ${ }^{4}$ and low concentrations. ${ }^{5}$ Ismail et $a l^{6}$ found lower testosterone concentrations in men with impotence of gradual onset and low sexual interest than in impotent men with normal sexual interest. This distinction was not found by Racey et al. ${ }^{7}$ The results of giving exogenous androgens for the treatment of impotence have been equally inconclusive. Two studies of uncertain validity claimed positive effects, ${ }^{89}$ while Cooper et $a l^{10}$ found only a small transient effect. In all these studies the androgens used were weak. Nevertheless, the complex determinants of sexual behaviour should encourage clinicians to investigate combinations of hormonal and psychological methods of treatment, as has been done successfully by Carney et $a l^{11}$ with sexually unresponsive women. The continuation of unresolved psychological factors could easily obscure a positive hormonal effect.

Thirty years ago Heller and Myers ${ }^{12}$ claimed successes from the treatment with androgens of impotence in older men with low testosterone and raised gonadotrophin concentrationsthe so-called "male climacteric syndrome." This claim received scant scientific attention until recently, when several studies found a common though not invariable decline in testicular function with advancing years. ${ }^{13} 14$ Though there is an association between impotence and advancing age, ${ }^{15} 16$ it remains to be seen whether this is a consequence of lowered testosterone concentrations and whether the impotence can be corrected with exogenous testosterone.

More commonly, however, men presenting with impotence and low testosterone concentrations have normal or low gonadotrophin concentrations-as in the hyperprolactinaemic men. This suggests a central rather than testicular basis. Mortimer et al $^{17}$ found that treating men with hypogonadism of hypothalamic origin with luteinising-hormone-releasing hormone (LH-RH) improved sexual function before there was any discernible effect on plasma testosterone concentrations. By contrast, some patients with Kallman's syndrome (which is thought to be due to a deficiency of $\mathrm{LH}-\mathrm{RH}$ ) respond sexually to exogenous androgens. ${ }^{3}$ Other studies of the effectiveness of LH-RH in treating impotence, though largely negative in their results, have failed to control for the pretreatment hormonal state, ${ }^{18}{ }^{19}$ and the treatment may prove effective in some cases.

Research into male sexual dysfunction has suffered from a 
tendency to regard impotent men as homogeneous from the endocrine, physiological, and psychological points of view. Our future research needs to pay more attention to their hormonal state and to the physiological nature of the dysfunction-failure of erection, ejaculation, or orgasm-and to the level of sexual interest or appetite.

1 Franks, S, et al, Clinical Endocrinology, 1978, 8, 277.

Thorner, M O, and Besser, G M, in Prolactin and Human Reproduction, ed P G Crosignani and C Robyn, p 285. London, Academic Press, 1977.

${ }^{3}$ Bancroft, J H J, and Skakkebaek, N, Sex, Hormones and Behaviour, Ciba Foundation Symposium No 62, March 1978. In press.

${ }^{4}$ Lawrence, D H, and Swyer, G I M, British Medical fournal, 1974, 1, 349.

${ }^{5}$ Raboch, J Mellan, J, and Starka, L, Archives of Sexual Behaviour, 1975, 4, 541 .

${ }^{6}$ Ismail, A A A, Davison, D W, and Loraine, J A, in Reproductive Endocrinology, ed W J Irvine, p 138. Edinburgh, Livingstone, 1970.

Racey, P A, et al, fournal of Endocrinology, 1973, 59, 23.

Bruhl, E E, and Leslie, C H, Medical Record and Annals, 1963, 56, 22.

Jakobovits, T, Fertility and Sterility, 1970, 21, 32.

10 Cooper, A J, et al, Irish fournal of Medical Science, 1973, 142, 155.

${ }^{11}$ Carney, P A, Bancroft, J H J, and Mathews, A M, British fournal of Psychiatry, 1978, 133, 339.

12 Heller, C G, and Myers, G B, Fournal of the American Medical Association, $1944,126,472$

${ }^{13}$ Vermeulen, A, Rubens, R, and Verdonck, L, fournal of Clinical Endocrinology and Metabolism, 1972, 34, 730 .

${ }^{14}$ Stearns, E L, et ul, American fournal of Medicine, 1974, 57, 761.

${ }_{15}$ Kinsey, A C, Pomeroy, W B, and Martin, C E, Sexual Behaviour in the Human Male. Philadelphia, Saunders, 1948.

16. Bancroft, J H J, and Coles, L, British Medical fournal, 1976, 1, 1575.

1: Mortimer, C H, et al, British Medical fournal, 1974, 4, 617.

18 Benkert, O, et al, Neuropsychobiology, 1975, 1, 203.

19 Davies, T F, et al, Clinical Endocrinology, 1976, 5, 601.

\section{Renal complications of connective tissue disease}

Kidney damage contributes greatly to the illness and death associated with connective tissue diseases. Its frequency is difficult to assess, however, because estimates depend on the sensitivity of the criteria used for diagnosis, the specialty of the investigators, and the care taken to separate the effects of the disease from those of treatment. This was just one of the problems discussed at a recent meeting of rheumatologists and nephrologists dealing with renal complications in connective tissue disease, the proceedings of which will be published shortly as a supplement to the European fournal of Rheumatology.

Estimates of deaths from renal complications in patients with rheumatoid disease varied from $4{ }_{0}^{\circ}$ to $22^{\circ} \%$ and evidence of renal disease was reported in up to $70 \%$. The types of kidney damage included the amyloid deposition found in rheumatoid disease; the vasculitis that occurs in scleroderma and polyarteritis; the tubulointerstitial disease of Sjögren's syndrome; and the immune complex deposition in glomeruli, seen most commonly in systemic lupus erythematosus. What causes immune complex glomerulonephritis? The size of the complexes, the IgG subclass and affinity of the antibody, and the capacity of the complexes to fix complement were some of the important factors discussed; and the meeting gave particular attention to the ability of the reticuloendothelial system to clear immune complexes.

Renal amyloidosis secondary to rheumatoid disease usually progresses to kidney failure, though some spontaneous remissions do occur. The amyloid appears to be derived from serum protein amyloid A (AA), a soluble protein with a molecular weight of 12500 . The concentration of this protein is raised in chronic inflammatory diseases, including the connective tissue diseases. In the tissues of normal people serum protein amyloid A is degraded to small peptides, but in peripheral monocytes from patients with secondary amyloidosis serum protein amyloid $\mathrm{A}$ is only partially degraded-to the insoluble fibrillar protein amyloid $\mathrm{A}$, which is the major component of amyloid. Long-term chlorambucil treatment of patients with juvenile rheumatoid arthritis may prevent death from renal amyloidosis, and the condition may even bring some benefit-renal transplantation in patients with secondary amyloidosis appears to be more often successful than in those with other forms of kidney disease.

Should treatment with gold and penicillamine be stopped once proteinuria appears? Although some rheumatologists took a more lenient view, nephrologists at the meeting argued that it should. In particular, patients who continue on penicillamine treatment despite proteinuria may develop a Goodpasture-like syndrome with crescentic glomerulonephritis and lung haemorrhages even though antibody to glomerular basement membrane is absent.

The nephrotoxicity of analgesics and other non-steroidal anti-inflammatory drugs is a controversial subject. Whereas phenacetin-induced kidney damage is an established phenomenon, there is no incontrovertible evidence that non-steroidal anti-inflammatory drugs can damage the kidney. When sensitive indices of tubular damage, such as tubular cell excretion, $N$-acetyl glucosaminidase excretion, and lowmolecular-weight proteinuria, are used most if not all of these drugs can be shown to damage renal tubules. But how relevant is this to chronic renal damage after prolonged use? Only time can tell. Now that many new anti-inflammatory drugs are being introduced, rheumatologists should remember that the dangers of phenacetin were not recognised for some 50 years. Patients on long-term treatment with non-steroidal anti-inflammatory drugs should perhaps have regular checks on kidney function by serial creatinine measurements so that nephropathy is not overlooked. Meanwhile those with rheumatoid and other connective tissue diseases should not be denied the undoubted benefits of these highly effective drugs.

\section{Nursing reform: shadow or substance?}

Doctors needed eight years and an independent inquiry to achieve reform of the General Medical Council. Nurses, midwives, and health visitors have just reached the Parliamentary stage in reforming their educational and registration procedures, eight years after the Briggs Committee ${ }^{1}$ started work "to review the role of the nurse and midwife in the hospital and the community and the education and training required for that role...." The Briggs Report was comprehensive, with 75 recommendations that included setting up a central body responsible for professional standards of education and discipline in nursing and midwifery; education boards for England, Scotland, and Wales; an 18-month basic nursing practice course; and a call for nurses in training to be students rather than pairs of hands.

Since the Committee on Nursing reported nurses have been urging the Government to act. Barbara Castle promised action in 1974. The Briggs Co-ordinating Committee, chaired by $\mathrm{Mr}$ Roland Moyle, Minister of State, was eventually set up 